\title{
Quantitative Trait Loci for Fusarium Head Blight Resistance in a Recombinant Inbred Population of Wangshuibai/Wheaton
}

\author{
J.-B. Yu, G.-H. Bai, W.-C. Zhou, Y.-H. Dong, and F. L. Kolb
}

First author: Department of Agronomy, Kansas State University, Manhattan 66506; second author: United States Department of AgricultureAgricultural Research Service, Plant Science and Entomology Research Unit, 4008 Throckmorton Hall, Manhattan, KS 66506; third author: Department of Biological Sciences, University of Alberta, Edmonton, T6G 2E9, Canada; fourth author: Department of Plant Pathology, University of Minnesota, St. Paul 55108; and fifth author: Department of Crop Sciences, University of Illinois, Urbana 61801. Accepted for publication 11 September 2007.

\begin{abstract}
Yu, J.-B., Bai, G.-H., Zhou, W.-C., Dong, Y.-H., and Kolb, F. L. 2008. Quantitative trait loci for Fusarium head blight resistance in a recombinant inbred population of Wangshuibai/Wheaton. Phytopathology 98:87-94

Use of diverse sources of Fusarium head blight (FHB)-resistant germplasm in breeding may significantly improve wheat resistance to FHB. Wangshuibai is an FHB-resistant Chinese landrace unrelated to cv. Sumai 3 , the most commonly used FHB-resistant source. In all, $139 \mathrm{~F}_{6}$ recombinant inbred lines were developed from a cross between Wangshuibai and an FHB-susceptible cultivar, Wheaton, to map quantitative trait loci (QTL) for wheat resistance to initial infection (type I resistance), spread of FHB symptoms within a spike (type II resistance), and deoxynivalenol (DON) accumulation (type III resistance) in infected grain. The experiments were conducted in a greenhouse at Manhattan, KS from 2003 to 2005. More than 1,300 simple-sequence repeat and amplified fragment

5AS, and 5DL after spray inoculation; seven QTL for type II resistance were identified on chromosomes 1A, 3BS, 3DL, 5AS, 5DL, and 7AL after point inoculation; and seven QTL for type III resistance were detected on chromosomes 1A, 1BL, 3BS, 5AS, 5DL, and 7AL with the data from both inoculation methods. These QTL jointly explained up to 31.7, 64 , and $52.8 \%$ of the phenotypic variation for the three types of FHB resistance, respectively. The narrow-sense heritabilities were low for type I resistance $(0.37$ to 0.41$)$ but moderately high for type II resistance $(0.45$ to 0.61$)$ and type III resistance (0.44 to 0.67$)$. The QTL on the distal end of 3BS, 5AS, and 5DL contributed to all three types of resistance. Two QTL, on 7AL and 1A, as well as one QTL near the centromere of 3BS (3BSc), showed effects on both type II and type III resistance. Selection for type II resistance may simultaneously improve type I and type III resistance as well. The QTL for FHB resistance identified in Wangshuibai have potential to be used to pyramid FHB-resistance QTL from different sources.
\end{abstract} length polymorphism markers were analyzed in this population. Five QTL for type I resistance were detected on chromosomes 3AS, 3BS, 4B,

Fusarium head blight (FHB), mainly caused by Fusarium graminearum, is an economically important disease of cereal crops and is prevalent in humid and semi-humid regions worldwide. FHB can greatly reduce grain yield (3). The invasion of the wheat kernel by the fungus results in destruction of its starch granules and storage proteins. In addition, accumulation of mycotoxins, especially deoxynivalenol (DON), in the infected grain can significantly reduce the price of grain at sale (37). DON was reported as a virulence factor to aid colonization of the pathogen in the host (12). DON and other trichothecenes also can function as inhibitors of protein synthesis, which exhibits deleterious effects on animal production and human health $(4,6)$.

Although application of fungicides is a method commonly used to reduce the losses caused by FHB in many wheat-growing areas, the application cost, pollution of the environment, and a low level of protection cause farmers to be dissatisfied with this method of control (23). In addition, application of some fungicides may even raise mycotoxin content in infected grain (28). FHB-resistant wheat cultivars can provide a more cost-effective and environmentally safe alternative to control the disease. Different types of FHB resistance have been described (21). Resistance to initial penetration by the pathogen (type I), resis-

Corresponding author: G.-H. Bai; E-mail address: guihua.bai@ars.usda.gov

doi:10.1094/PHYTO-98-1-0087

This article is in the public domain and not copyrightable. It may be freely reprinted with customary crediting of the source. The American Phytopathological Society, 2008.
Additional keywords: simple-sequence repeats. tance to spread of FHB symptoms within an infected spike (type II), and resistance to the accumulation of DON (type III) have drawn the most attention (30). Among them, type II resistance has proven to be more stable than type I resistance in most of the resistant cultivars identified to date (4). Although complete resistance to FHB has not been found in wheat, wheat cultivars with various degrees of type II resistance have been reported from Europe, Asia, and America and have been used extensively in genetics studies $(7,8,18)$. Quantitative trait loci (QTL) for FHB resistance, mainly for type II resistance that was evaluated by using point inoculation, have been reported in Chinese cultivars such as Sumai 3 and Ning 7840, and in a few other resistant cultivars from Brazil and Europe. Most of these studies located a major QTL for wheat FHB resistance on chromosome 3BS and several minor QTL on 2DL, 4B, 5AS, and 6BS (7).

In contrast to type II resistance, type I resistance usually is evaluated by calculating incidence, such as the proportion of the infected florets (PIF) in a spray-inoculated spike (30) or the proportion of infected spikes (PIS) in a field plot where inoculation was done by scattering infected grain on the ground $(4,17)$. QTL for type I resistance have been reported in Sumai 3 (38), Frontana (34), and Goldfield (10), but no common QTL was found for type I resistance among these cultivars.

DON has been considered a virulence factor for FHB infection (1). Fusarium mutants with a disrupted trichodiene synthase (Tri5) gene, which is necessary for trichothecene biosynthesis, showed reduced virulence on wheat and were unable to spread from the inoculated spikelet to uninoculated spikelets in the same spike (1). DON may move ahead of the fungus in an infected 
plant and play a role in facilitating colonization of host tissue by the fungus (13). Jansen et al. (12) reported that the Fusarium fungus may not be able to move into rachis in the absence of DON because strong cell wall fortifications may develop in the rachis node. QTL controlling type III resistance have been reported on chromosomes 2A, 2DS, 3BS, 5AS, 4BL, 5AL, and 7A in wheat cvs. Maringa, Ernie, and W14, as well as Sumai 3 and its derivatives (7).

Glycosylation was reported to play an important role in reducing DON content conferred by the QTL for type II resistance on 3BS (15); however, Somers et al. (30) found that the QTL for low DON accumulation on 2DS and 5AS in Maringa might be independent from the QTL of other types of FHB resistance. Wangshuibai is an FHB-resistant Chinese landrace unrelated to Sumai $3(2,16,39)$. To date, 10 and 11 chromosome regions have
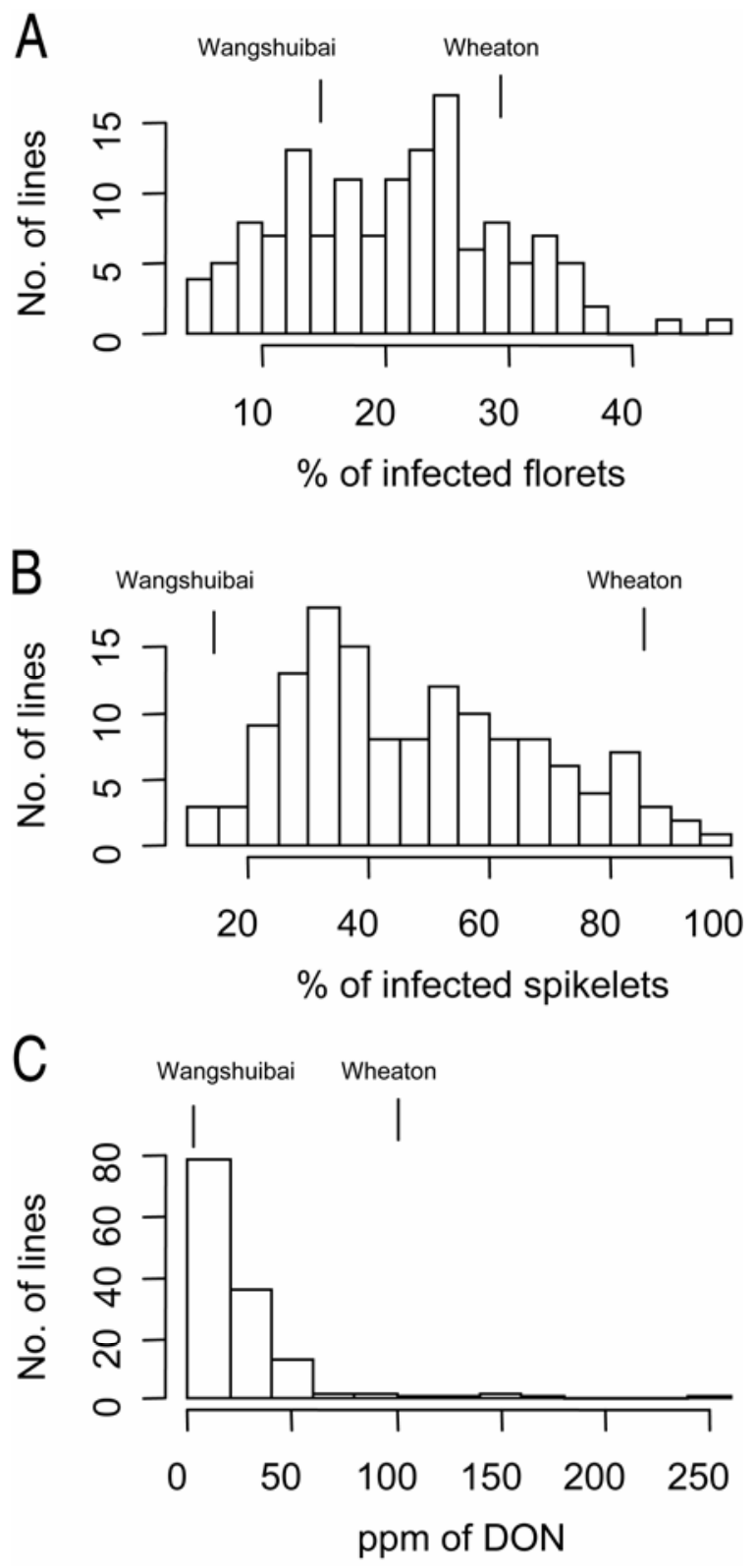

Fig. 1. Histograms to show the frequency distribution of mean proportion of infected florets, proportion of symptomatic spikelets, and deoxynivalenol (DON) content in 139 recombinant inbred lines for $\mathbf{A}$, type I resistance based on the data from spray-inoculation experiments; B, type II resistance based on the data from point-inoculation experiments; and $\mathbf{C}$, type III resistance based on DON content in harvested grain. Proportion of infected florets, proportion of symptomatic spikelets, and DON content of parents are indicated. All experiments were conducted in the greenhouses of Kansas State University, Manhattan. been associated with type I and type II resistance, respectively, in Wangshuibai. Because most of the experiments were conducted in the field (17), environmental factors may have affected the disease evaluation. Also, the low DON content has been characterized only under field conditions in one previous study (19). In this study, a population of recombinant inbred lines (RIL) derived from Wangshuibai/Wheaton was evaluated repeatedly for all three types of FHB resistance under controlled greenhouse conditions in order to identify the QTL involved in wheat FHB resistance, especially for type III resistance.

\section{MATERIALS AND METHODS}

Plant materials and pathogen. An $\mathrm{F}_{6}$ population of $139 \mathrm{RIL}$ was developed by single-seed descent from a cross between Wangshuibai and Wheaton. Wangshuibai is a highly FHB-resistant Chinese landrace, and Wheaton is a hard red spring, FHBsusceptible cultivar released from the University of Minnesota, St. Paul. All RIL were evaluated for FHB resistance in a greenhouse at Kansas State University, Manhattan, from 2003 to 2005, as described by Bai et al. (1). Each experiment had three replications. An aggressive F. graminearum field isolate (GZ 3639) with high DON production from Kansas was used in this study (1).

Evaluation of FHB and DON content. The RIL were prepared for inoculation as follows: after vernalization at $4{ }^{\circ} \mathrm{C}$ in a growth chamber for 8 weeks, six seedlings were transplanted into a 5-by-5 in. Dura-pot (Hummert Int., St. Louis) containing Metro Mix 360 soil mix (Hummert Int.) and grown in a greenhouse with a 12-h day length. A single spike was inoculated on each plant at anthesis (Feekes growth stage 10.51) in each plot, and the plants were incubated in a moist chamber for 3 days to initiate infection. The inoculated plants then were moved to their original bench position and grown at $25 \pm 5^{\circ} \mathrm{C}$ (day) and $17 \pm 5^{\circ} \mathrm{C}$ (night). Type I resistance was evaluated in two greenhouse experiments, in spring 2004 and 2005, by spraying $1 \mathrm{ml}$ of a spore suspension of $F$. graminearum $(1,000$ conidia spores $/ \mathrm{ml})$ on each selected spike. To avoid confounding by type II resistance, the infected and total numbers of florets in the spike were counted at 7 days after inoculation (dai) to calculate PIF. Type II resistance was measured in three greenhouse experiments in spring 2003, fall 2003, and spring 2005 by using a syringe to inject 1,000 conidia spores of $F$. graminearum into a central floret of a spike at anthesis (point-inoculation), counting the infected and total spikelets in an inoculated spike at 21 dai, and then calculating the proportion of symptomatic spikelets (PSS) as the final disease severity. DON content was determined by quantifying the amount of DON (milligrams of DON per kilogram of wheat grains, or parts per million [ppm]) in the grain harvested at maturity from Fusariuminoculated spikes by gas chromatography-mass spectrometry (GC-MS) (22). DON data were collected from two point-inoculation experiments (spring and fall 2003) and two spray-inoculation experiments (spring 2004 and spring 2005).

Amplified fragment length polymorphism analysis. The genomic DNA of each RIL was isolated from leaf tissue by using the cetyltrimethylammonium bromide method (26). Amplified fragment length polymorphism (AFLP) analysis was carried out as described by Bai et al. (2). DNA from the parents, a bulk of the 10 most-resistant RIL, and a bulk of the 10 most-susceptible RIL were screened with 110 primer combinations between 15 IRD700/800-dye-labeled PstI primers and 29 MseI primers. Polymorphic primers between the two bulks were chosen to screen the population. The AFLPs were analyzed in a Li-Cor 4200 DNA analyzer by using $6.5 \%$ gel matrix and were scored with Saga software (Li-Cor, Inc., Lincoln, NE).

Analysis of simple sequence repeats. In total, $\approx 1,300$ simplesequence repeats (SSRs) from different research groups, including WMC (31), GWM (25), BARC (32), CFA and CFD (11,33), and GDM (24), were screened for polymorphism between the parental 
lines, and a total of 248 polymorphic SSR markers were selected to analyze the mapping population according to Bai et al. (2).

Experimental design and data analysis. The variance analyses on disease severities from each experiment and across all three experiments were performed using the GLM procedure of
SAS (SAS Institute Inc., Cary, NC). All experiments were arranged in a randomized complete-block design. Because the dominance variance was negligible and the confounding effect of the additive-by-additive genetic variance could be included in the heritability estimate at the $\mathrm{F}_{6}$ level of inbreeding, narrow-sense

TABLE 1. Narrow-sense heritabilities and analysis of variance for proportion of infected florets (PIF), proportion of symptomatic spikelets (PSS), and deoxynivalenol (DON) content estimated from greenhouse experiments conducted in Manhattan, KS in 2003 to $2005^{\mathrm{y}}$

\begin{tabular}{|c|c|c|c|c|c|}
\hline Trait, variable ${ }^{z}$ & $\mathrm{df}$ & MS & $F$ value & $P$ value & $h^{2}$ \\
\hline PIF & $\ldots$ & $\ldots$ & $\ldots$ & $\ldots$ & $0.37-0.41$ \\
\hline Experiments & 1 & 624.7 & 6.27 & $<0.01$ & $\ldots$ \\
\hline RIL & 137 & 283.8 & 2.85 & $<0.01$ & $\ldots$ \\
\hline Error & 394 & 99.6 & $\ldots$ & $\ldots$ & $\ldots$ \\
\hline PSS & & $\ldots$ & $\ldots$ & $\ldots$ & $0.45-0.61$ \\
\hline Experiments & 2 & $25,648.42$ & 72 & $<0.01$ & $\ldots$ \\
\hline RIL & 137 & $2,378.19$ & 6.68 & $<0.01$ & $\ldots$ \\
\hline DON & & $\ldots$ & $\ldots$ & $\ldots$ & $0.44-0.67$ \\
\hline Experiments & 3 & 11.582 & 76.25 & $<0.01$ & $\ldots$ \\
\hline RIL & 137 & 0.8934 & 5.88 & $<0.01$ & $\ldots$ \\
\hline RIL $\times$ experiments & 409 & 0.2635 & 1.73 & $<0.01$ & $\ldots$ \\
\hline Error & 534 & 0.1519 & $\ldots$ & $\ldots$ & $\ldots$ \\
\hline
\end{tabular}

${ }^{y}$ Abbreviations: $\mathrm{df}=$ degree of freedom, MS = mean square, and $h^{2}=$ the range of narrow-sense heritabilities.

${ }^{\mathrm{z}} \mathrm{RIL}=$ recombinant inbred lines.

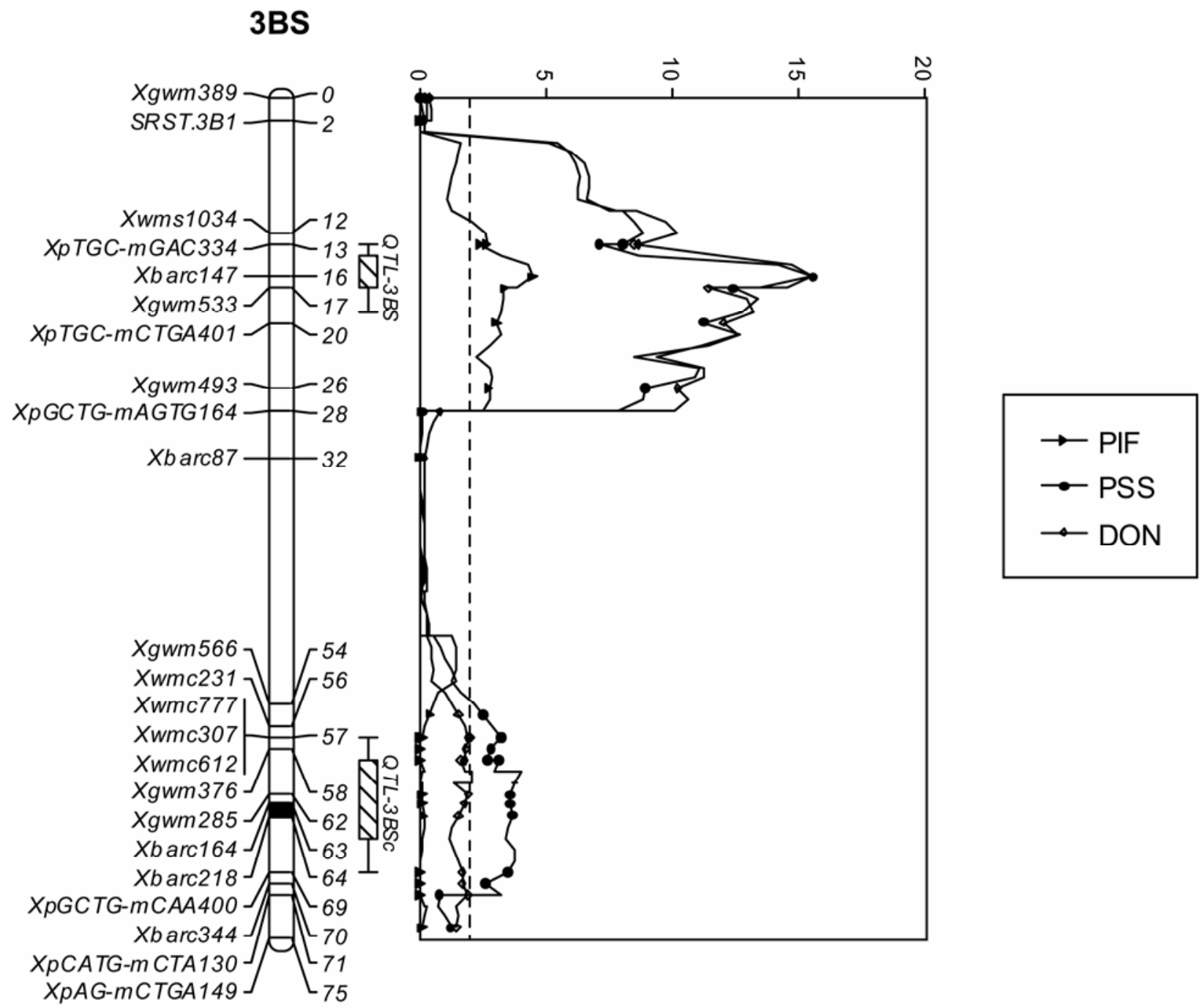

Fig. 2. Log-likelihood odds (LOD) contours obtained from composite interval mapping with averages based on combined data from greenhouse experiments conducted in Manhattan, KS, showing the quantitative trait loci for low proportion of infected florets (PIF), low proportion of symptomatic spikelets (PSS), and low deoxynivalenol (DON) content on chromosome 3BS. The black solid bar indicates the approximate location of the centromere. 
heritabilities of the three FHB resistance traits were estimated using the formula $h^{2}=\delta_{g}^{2} / \delta_{p}^{2}$, where $h^{2}$ is narrow-sense heritability, $\delta_{p}^{2}$ is phenotypic variance $\left(\delta_{p}^{2}=\delta_{g}^{2}+\delta_{E}^{2}\right)$, and $\delta_{g}^{2}$ is genetic variance $\left(\delta_{g}^{2}=\left(\delta_{L}^{2}-\delta_{E}^{2}\right) / r\right.$, where $\delta_{L}^{2}$ is the variance of the RIL, $\delta_{E}^{2}$ is error variance, and $\mathrm{r}$ is number of replications. All the parameters were obtained from the analysis of variance (ANOVA) table according to Singh et al. (29).

Linkage maps of AFLP and SSR were constructed with JoinMap 3.0 (35) by using the Kosambi mapping function (14). A minimum logarithm of odds (LOD) threshold of 3 was used to determine linkage groups. The QTL analyses were conducted separately for FHB symptom and DON content data. The simple interval mapping (SIM) and composite interval mapping (CIM) were performed on the individual line means from each experiment and on the overall line means across all experiments by using WinQTLCart 2.5 (36). Five markers and a 10-centimorgan window size were used as a background control in CIM analysis. Permutation tests were performed to estimate appropriate significant thresholds for both SIM and CIM (9). Based on 1,000 permutations, a LOD threshold of 2.0 was set to declare a significant QTL in both SIM and CIM. Determination coefficients $\left(R^{2}\right)$ for each QTL were calculated through multiple linear regression using SAS REG procedure.

\section{RESULTS AND DISCUSSION}

FHB and DON content in RIL. The frequency distributions for mean PIF (type I resistance), mean PSS (type II resistance), and mean DON content (type III resistance) were continuous, with broad phenotypic variation among the RIL (Fig. 1), especially for PSS and DON content. The mean PSS ranged from 12.8 to $100 \%$ across the three experiments in which point-inoculation was used, and the mean PIF ranged from 9.6 to $39.5 \%$ over the two experiments in which plants were spray inoculated. The mean DON content in inoculated spikes varied from 2.72 to $243 \mathrm{ppm}$ among RIL over the four experiments. Normality tests using the PROC UNIVARIATE procedure of SAS indicated that DON content deviated from a normal distribution whereas type I and type II resistance scores did not (data not shown); therefore, logarithmtransformed DON data were used in further statistical analysis.

The variances of experiment, genotype, and experiment-genotype interaction were significant for the three traits. The ANOVA showed a highly significant effect for experiment, genotype, and genotype-experiment interaction for both PSS and DON content $(P \leq 0.01)$. The PIF data had a highly significant effect for genotype and genotype-experiment interaction $(P<0.01)$, but had a relatively low significant effect for experiment $(P<0.01)$ (Table 1 ). The correlation coefficients ranged from 0.53 (between fall 2003 and spring 2005 experiments) to 0.61 (between spring and fall 2003 experiments) at a significant level of $P<0.01$ for PSS among the three point-inoculation experiments and from 0.34 to $0.52(P<0.01)$ for DON content among the four experiments. Average DON content of RIL in point-inoculation experiments $(14.2 \mathrm{ppm})$ was $\approx 49 \%$ of that in spray inoculation experiments $(27.9 \mathrm{ppm})$. The correlation coefficient was $0.23(P<0.01)$ for

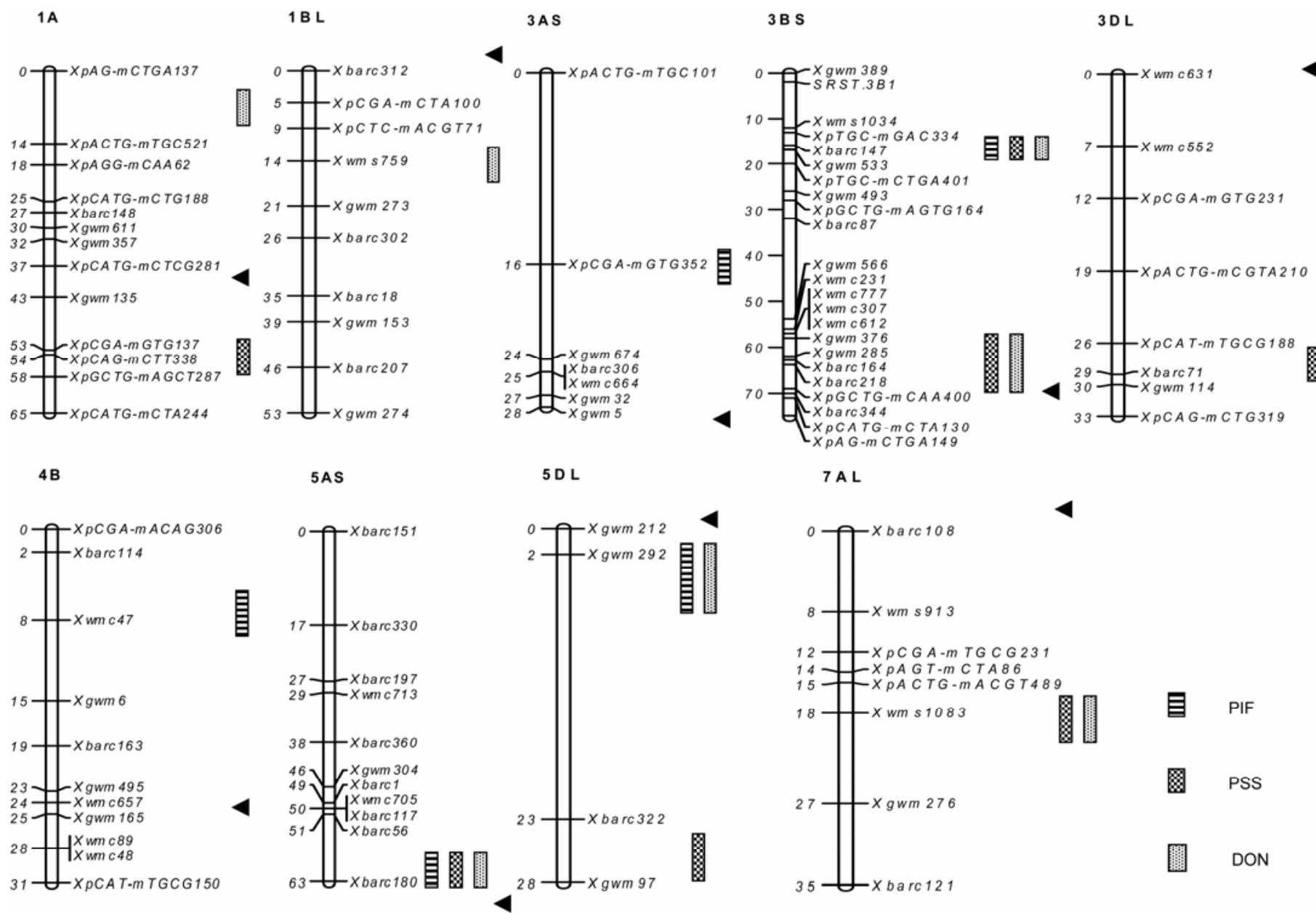

Fig. 3. Chromosome locations of quantitative trait loci detected through composite interval mapping using data from the greenhouses experiment conducted in Manhattan, KS. The numbers on the left of each linkage group map are genetic distance in centimorgans and the letters on the right of each linkage group map are marker names. The peak regions of quantitative trait loci for low proportion of infected florets (PIF), low proportion of symptomatic spikelets (PSS), and low deoxynivalenol (DON) content are indicated with bars and their lengths represent 1-log-likelihood odds support interval. The approximate locations of centromere are indicated with solid arrows. 
PIF between the two spray-inoculation experiments. The narrowsense heritabilities of the three FHB resistance traits estimated from all experiments were low for type I but relatively high for type II and type III resistance (Table 1). The results indicate that type I resistance is less repeatable with higher nongenetic variation than type II and type III resistance even when measured in a greenhouse where temperature and moisture were controlled. The correlations ranged from 0.68 to $0.78(P<0.01)$ between PSS and DON content in the three point-inoculation experiments and 0.31 and $0.48(P<0.01)$ between PIF and DON content in the two spray-inoculation experiments. The results suggested that type III resistance was due mainly to a high level of type II resistance (fewer infected spikelets in an infected spike), and not due to type I resistance (number of initially infected spikelets in a spike). Type II resistance appears to be a stable resistance component and, therefore, more important than type I resistance. In breeding programs, selection for type II resistance may lower DON content and improve overall FHB resistance of new cultivars.

QTL for type I resistance. Type I resistance usually is measured under natural infection conditions where abundant inoculum is available to randomly infect any floret on any spike in a field plot. It usually is rated as proportion of infected spikes in a plot, or as how many florets are initially infected by the fungus in a spike. In this experiment, type I resistance was evaluated in the greenhouse where spray inoculation was intended to simulate natural infection. After spray inoculation, all inoculated spikes showed infection, but the numbers of initially infected spikelets were different among RIL. Therefore, PIF in a spike was used to reflect type I resistance in this study.

Composite interval mapping of PIF from a single experiment or from data combined over the two experiments detected five QTL for type I resistance, on chromosomes $3 \mathrm{AS}, 3 \mathrm{BS}, 4 \mathrm{~B}, 5 \mathrm{AS}$, and 5DL (Figs. 2 and 3). Each of the five QTL was significant in only one of the two experiments, which agrees with low heritability of type I resistance as described previously. The QTL on 3BS and 5DL also were significant when the mean over the two experiments was used (Figs. 2 and 3; Table 2). The QTL on 3BS, 3AS, and $4 \mathrm{~B}$ have relatively larger effects than the others, based on single-year data (Table 2). Four QTL for type I resistance were from Wangshuibai and one on chromosome 4B was from Wheaton.

QTL for type II resistance. Type II resistance was evaluated in three experiments. Composite interval mapping using PSS from a single experiment or combined PSS from three experiments detected seven significant QTL for type II resistance, on chromosomes 1AS, 3BS (Figs. 2 and 3), 3DL, 5AS, 5DL, and 7AL (Fig. 3, Table 2). One of the QTL on 3BS showed the largest effect in all three experiments (Table 2). This QTL explained 17.6 to $26.5 \%$ of the phenotypic variation in individual experiments and $33.9 \%$ of the phenotypic variation when data were combined from all three experiments. Another QTL significant in all three experiments was on 3DL, and it explained 5.2 to $9.7 \%$ of the phenotypic variation. The other five QTL were significant in only one or two experiments, and exhibited relatively smaller effects on type II resistance (Table 2). The QTL on 5DL was significant in only one experiment and not significant when the mean over three experiments was used; therefore, this QTL may be the least reliable one for type II resistance. Of the seven putative QTL detected for type II resistance, four QTL (on 3BS, 3BSc, 5AS, and $7 \mathrm{AL}$ ) were in the same genomic regions as those for either type I resistance or low DON content (Table 2; Fig. 3).

Among the seven QTL for type II resistance, five were consistent in at least two experiments. The QTL on 1A and 5DL each were detected in only one experiment and had only minor effect. The 3BS QTL was detected in other Wangshuibai-derived mapping populations but explained less phenotypic variation (9.0 to $23.8 \%)$ than it did in this study for type II resistance $(16,19$, 20). This might be due to larger environmental effects on type II resistance in the field than in the greenhouse. Based on cross-

TABLE 2. Phenotypic effects of markers linked to the quantitative train loci (QTL) for three types of Fusarium head blight resistance in the recombinant inbred population of Wangshuibai/Wheaton estimated by multiple regressions from three point-inoculation experiments (spring 2003, fall 2003, and 2005) and two sprayinoculation experiments (2004 and 2005) conducted in Manhattan, $\mathrm{KS}^{\mathrm{x}}$

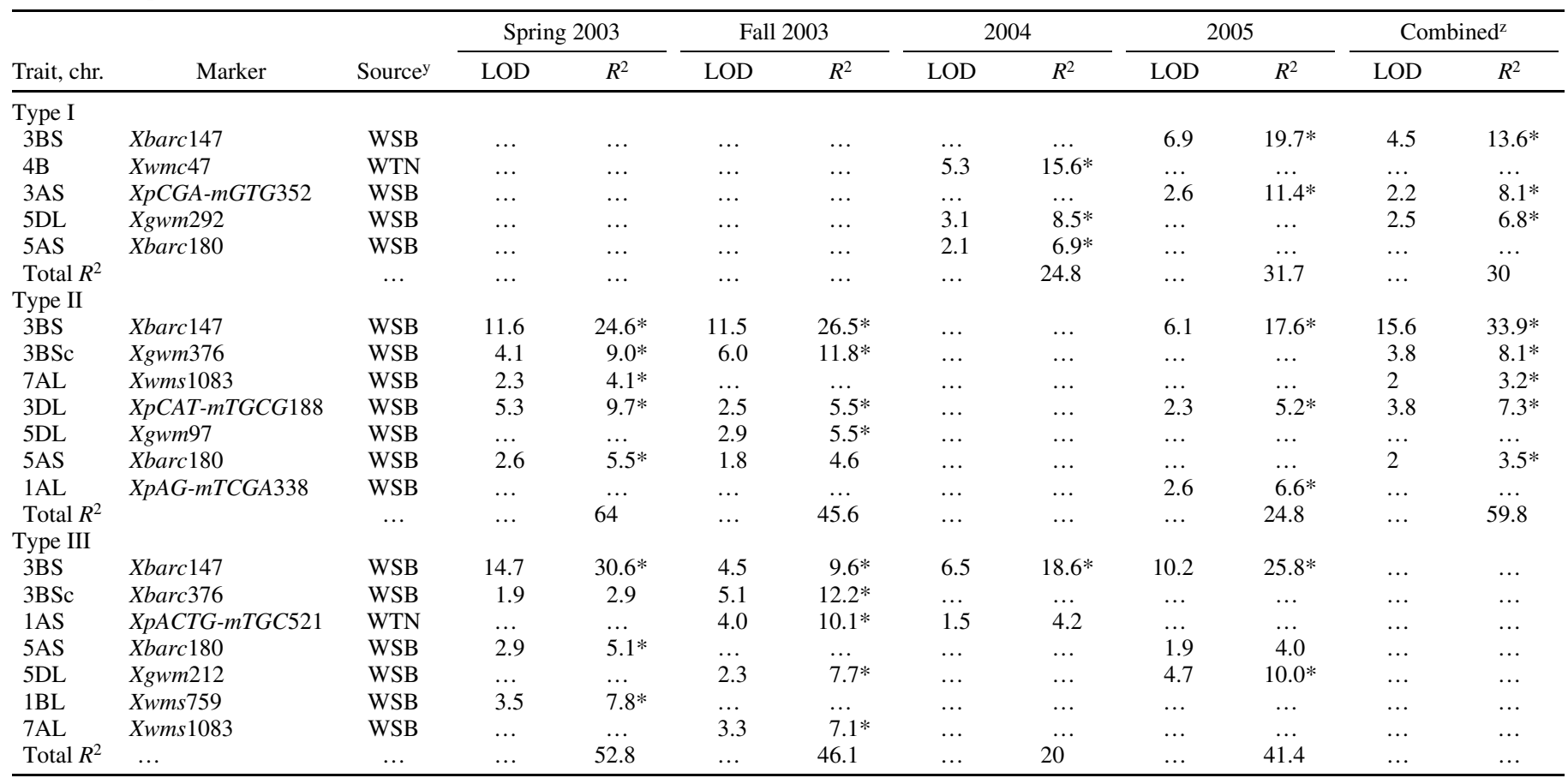

${ }^{\mathrm{x}}$ chr. $=$ Chromosome, LOD $=$ logarithm of odds, and asterisk $(*)=$ significant QTL $(P<0.05)$.

${ }^{\mathrm{y}}$ WSB $=$ QTL allele for Fusarium head blight resistance (type I and type II) or low deoxynivalenol content (type III) from Wangshuibai and WTN $=$ QTL allele for Fusarium head blight resistance or low deoxynivalenol content from Wheaton.

${ }^{\mathrm{z}}$ QTL effects calculated based on the means over two experiments for proportion of infected florets and three experiments for proportion of symptomatic spikelets, respectively. 
TABLE 3. Mean proportion of symptomatic spikelets of recombinant inbred lines carrying marker loci that linked to quantitative trait loci on 3BS, 5AS, and 5DL for type II resistance to Fusarium graminearum in the wheat population of Wangshuibai/Wheaton based on data from spring 2003, fall 2003, and spring 2005 point-inoculation experiments conducted in Manhattan, KS ${ }^{y}$

\begin{tabular}{|c|c|c|c|c|}
\hline Marker locus, genotype ${ }^{z}$ & $\begin{array}{c}\text { Spring } \\
2003\end{array}$ & $\begin{array}{l}\text { Fall } \\
2003\end{array}$ & 2005 & Mean \\
\hline \multicolumn{5}{|l|}{ Xbarc147 (3BS) } \\
\hline $\mathrm{A}(\mathrm{R})$ & 34.5 & 26.6 & 51.7 & 35.3 \\
\hline $\mathrm{B}(\mathrm{S})$ & 66 & 56.6 & 71.3 & 60.4 \\
\hline dif & 31.5 & 30 & 19.6 & 25.1 \\
\hline \multicolumn{5}{|l|}{ Xbarc180 (5AS) } \\
\hline$A(R)$ & 40.5 & 33.9 & 58.9 & 42.2 \\
\hline $\mathrm{B}(\mathrm{S})$ & 53.3 & 43.9 & 61.8 & 49.6 \\
\hline dif & 12.8 & 10 & 2.9 & 7.4 \\
\hline \multicolumn{5}{|l|}{ Xgwm292 (5DL) } \\
\hline $\mathrm{A}(\mathrm{R})$ & 40.5 & 33.9 & 58.9 & 42.2 \\
\hline $\mathrm{B}(\mathrm{S})$ & 53.3 & 43.9 & 61.8 & 49.6 \\
\hline dif & 12.8 & 10 & 2.9 & 7.4 \\
\hline \multicolumn{5}{|l|}{ Xbarc147/Xbarc180 } \\
\hline $\mathrm{A} / \mathrm{A}(\mathrm{R} / \mathrm{R})$ & $29.9 \mathrm{a}$ & $26.3 \mathrm{a}$ & $54.2 \mathrm{a}$ & $35.1 \mathrm{a}$ \\
\hline $\mathrm{A} / \mathrm{B}(\mathrm{R} / \mathrm{S})$ & $37.4 \mathrm{a}$ & $26.8 \mathrm{a}$ & $51.0 \mathrm{a}$ & $36.0 \mathrm{a}$ \\
\hline $\mathrm{B} / \mathrm{A}(\mathrm{S} / \mathrm{R})$ & $62.9 \mathrm{~b}$ & $48.8 \mathrm{~b}$ & $70.2 \mathrm{~b}$ & $56.3 \mathrm{~b}$ \\
\hline $\mathrm{B} / \mathrm{B}(\mathrm{S} / \mathrm{S})$ & $70.0 \mathrm{~b}$ & $60.3 \mathrm{~b}$ & $72.9 \mathrm{~b}$ & $63.4 \mathrm{~b}$ \\
\hline dif & 40.1 & 34 & 21.9 & 28.3 \\
\hline \multicolumn{5}{|l|}{ Xbarc147/Xgwm292 } \\
\hline $\mathrm{A} / \mathrm{A}(\mathrm{R} / \mathrm{R})$ & $28.5 \mathrm{a}$ & $24.1 \mathrm{a}$ & $49.5 \mathrm{a}$ & $32.4 \mathrm{a}$ \\
\hline $\mathrm{A} / \mathrm{B}(\mathrm{R} / \mathrm{S})$ & $44.5 \mathrm{~b}$ & $30.8 \mathrm{~b}$ & $55.5 \mathrm{ab}$ & $40.2 \mathrm{ab}$ \\
\hline $\mathrm{B} / \mathrm{A}(\mathrm{S} / \mathrm{R})$ & $58.8 \mathrm{c}$ & $49.1 \mathrm{c}$ & $64.4 \mathrm{~b}$ & $55.2 \mathrm{c}$ \\
\hline $\mathrm{B} / \mathrm{B}(\mathrm{S} / \mathrm{S})$ & $74.8 \mathrm{~d}$ & $65.1 \mathrm{~d}$ & $79.3 \mathrm{c}$ & $66.5 \mathrm{~d}$ \\
\hline dif & 46.3 & 41 & 29.8 & 34.1 \\
\hline \multicolumn{5}{|c|}{ Xbarc147/Xbarc180/Xgwm 292} \\
\hline A/A/A (R/R/R) & $24.4 \mathrm{a}$ & $19.2 \mathrm{a}$ & $46.6 \mathrm{a}$ & $28.9 \mathrm{a}$ \\
\hline $\mathrm{A} / \mathrm{A} / \mathrm{B}(\mathrm{R} / \mathrm{R} / \mathrm{S})$ & $41.2 \mathrm{abc}$ & $23.2 \mathrm{ab}$ & $48.1 \mathrm{a}$ & $36.0 \mathrm{ab}$ \\
\hline $\mathrm{A} / \mathrm{B} / \mathrm{A}(\mathrm{R} / \mathrm{S} / \mathrm{R})$ & $33.4 \mathrm{ab}$ & $35.1 \mathrm{abc}$ & $54.4 \mathrm{ab}$ & $38.1 \mathrm{abc}$ \\
\hline $\mathrm{A} / \mathrm{B} / \mathrm{B}(\mathrm{R} / \mathrm{S} / \mathrm{S})$ & $48.1 \mathrm{bcd}$ & $38.4 \mathrm{bc}$ & $67.6 \mathrm{abc}$ & $46.3 \mathrm{bc}$ \\
\hline B/A/A (S/R/R) & $44.7 \mathrm{bc}$ & $28.1 \mathrm{ab}$ & $52.9 \mathrm{ab}$ & $41.6 \mathrm{abc}$ \\
\hline $\mathrm{B} / \mathrm{A} / \mathrm{B}(\mathrm{S} / \mathrm{R} / \mathrm{S})$ & 72.6 ef & $61.5 \mathrm{de}$ & $79.3 \mathrm{~d}$ & $64.3 \mathrm{de}$ \\
\hline B/B/A (S/S/R) & $66.0 \mathrm{de}$ & $57.7 \mathrm{~d}$ & $71.7 \mathrm{bc}$ & $61.0 \mathrm{de}$ \\
\hline B/B/B (S/S/S) & $84.9 \mathrm{f}$ & $78.2 \mathrm{e}$ & $81.0 \mathrm{~d}$ & $73.7 \mathrm{e}$ \\
\hline dif & 60.5 & 59 & 34.4 & 44.8 \\
\hline
\end{tabular}

y Different letters indicate significant difference at $P<0.05$.

${ }^{\mathrm{z}} \mathrm{A}=$ Wangshuibai, $\mathrm{B}=$ Wheaton, and dif = phenotypic difference between genotype means. A and B represent the resistant (R) and susceptible (S) alleles of the linked markers.

referenced markers, the 3BS QTL in Wangshuibai is most likely the same as Fhbl (syn. Qfhs.ndsu-3BS) in Sumai 3 (8), but a different allele, because the QTL in Wangshuibai had a smaller effect in different genetic backgrounds than that of Sumai 3, and the haplotype pattern of the SSR markers linked to the QTL in Wangshuibai was different from that of Sumai 3 (39). The QTL on 3BSc and 5AS had minor effects on type II resistance. These three QTL have been reported from Wangshuibai and other cultivars, such as Sumai 3, CM-82036, ND2603, Maringa, Renan, and W14 (7,16,30). The QTL on 3DL detected in this study might be the same QTL as Qfhs.nau-3D reported in Wangshuibai by Lin et al. (16). Three other QTL, on 1A, 5DL, and 7AL, demonstrated minor effects on type II resistance and seem to be new QTL.

The three markers linked to QTL that affected all three types of resistance, on 3BS, 5AS, and 5DL, were chosen to evaluate their genotypic effects on type II resistance (Table 3 ). The resistance allele of Xbarc147 showed the largest effect on FHB resistance among the three markers, which gave $25.1 \%$ reduction in PSS. The mean PSS of the RIL with one of the three resistance marker alleles was lower than the mean PSS of those RIL without any of the resistance marker alleles. The mean PSS value of RIL with all three resistance marker alleles was $28.9 \%$, whereas the mean PSS for the RIL with all three susceptible marker alleles was $73.7 \%$. Marker-assisted selection for the three QTL using a single marker per QTL could reduce $\approx 45 \%$ PSS in the Wheaton genetic background. If flanking markers for the QTL are used, a higher selection gain can be expected.

QTL for type III resistance. Seven QTL for type III resistance were detected, on chromosomes 1AS, 1BL, 3BS (2 QTL), 5AS, 5DL, and 7AL in four experiments - two designed to detect type I resistance and two designed to detect type II resistance. The QTL on 3BS showed the largest effect in all the experiments and explained 9.6 to $30.6 \%$ of phenotypic variation across four experiments (Table 2). The other six QTL exhibited relatively smaller effects on type III resistance, with $R^{2}$ values ranging from 3.6 to $12.2 \%$. The QTL on $1 \mathrm{AS}, 1 \mathrm{BL}$, and 7AL were detected only in a single experiment. The QTL on 3BS, 3BSc, 5AS, 5DL, and 7AL also showed significant effects on type I or type II resistance (Figs. 2 and 3; Table 2). The location of the QTL on 1AS for low DON content was different from that for type II resistance on the same chromosome. The QTL for type II resistance on 1AL was from Wangshuibai, whereas the QTL for type III resistance on 1AS was from Wheaton. In addition, the QTL on 1BL was detected only in the spring 2003 experiment and explained $7.8 \%$ of phenotypic variation for type III resistance (Table 2).

The minor QTL on 1BL from Wangshuibai in the same population used in this study showed a minor effect on type II resistance when it was tested in the greenhouse at the University of Illinois (40). This QTL also was mapped in wheat cv. Fundulea 201R (27). Therefore, this QTL for lower DON also may have an effect on type II resistance. It was not detected in this experiment because the effect of the QTL was weak and more vulnerable to nongenetic variations. The QTL on 1A for low DON seems to be different from that for type II resistance on 1AS; however, the LOD contours also shows a peak for type II resistance in this chromosome region, although it is not statistically significant. Thus, it is possible that the QTL for type III resistance on 1A was because of type II resistance. The peak of 5DL QTL for type III resistance overlapped with type I resistance, indicating that the QTL for type I resistance also might have an impact on type III resistance in the Wangshuibai/Wheaton population. Thus, type III resistance may not be an independent trait; it may be the consequence of both type II and type I resistance. Selection for type I or type II resistance most likely leads to a reduction in DON content in wheat cultivars.

Three QTL-linked marker loci (Table 4) were chosen to estimate their effectiveness for marker-assisted selection. When RIL contained all three resistant alleles, their mean DON content was $6.7 \mathrm{ppm}$, whereas the mean DON content of all the RIL carrying all three susceptible alleles in the population was 66.5 ppm. The Wangshuibai allele of Xbarc147 showed the largest effect on low DON, and the Wangshuibai allele of Xgwm212 was the second. The results indicated that marker-assisted selection of one marker each for the three QTL can significantly reduce the DON content in wheat grain.

Relationship among FHB resistance traits in Wangshuibai. Environmental conditions for evaluation of FHB resistance may affect the set of FHB-resistance QTL detected. Previous studies indicated that type I and type II resistance might be controlled by different QTL under field conditions $(17,34)$. In this study, the QTL on 3BS had the largest effect on both type I and type II resistance under greenhouse conditions. This differed from the results reported by Lin et al. (17) in that 3BS QTL was not significant for type I resistance under field conditions. A QTL on $5 \mathrm{AS}$ also showed effects on both type I and type II resistance in our study and in previous studies $(7,30)$. Thus, the major QTL on $3 \mathrm{BS}$ and some other minor QTL for type II resistance also have effects on type I resistance. The QTL on 1A, 3AS, 3DL, $4 \mathrm{BS}$, and 7AL were detected for only one type of resistance, indicating that the expression of different types of resistance may be modified by different QTL. These modifying QTL usually showed minor effects and may be more vulnerable to non- 


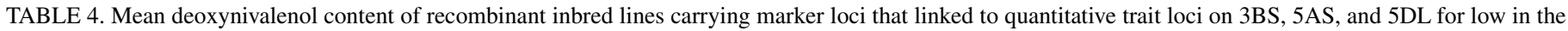

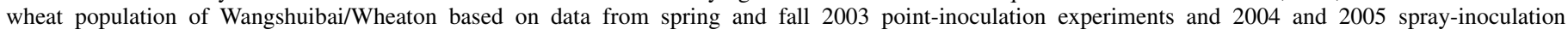
experiments conducted in Manhattan, $\mathrm{KS}^{\mathrm{y}}$

\begin{tabular}{|c|c|c|c|c|c|}
\hline Locus, genotype ${ }^{z}$ & Spring 2003 & Fall 2003 & 2004 & 2005 & Mean \\
\hline \multicolumn{6}{|l|}{ Xbarc147 (3BS) } \\
\hline $\mathrm{A}(\mathrm{R})$ & 5 & 6.8 & 20.9 & 12.3 & 11.2 \\
\hline $\mathrm{B}(\mathrm{S})$ & 25.2 & 25.7 & 48.9 & 36 & 33.8 \\
\hline dif & 20.2 & 18.9 & 28 & 23.7 & 22.6 \\
\hline \multicolumn{6}{|l|}{ Xbarc $180(5 \mathrm{AS})$} \\
\hline $\mathrm{A}(\mathrm{R})$ & 6.9 & 9.7 & 19.7 & 18.4 & 13.7 \\
\hline $\mathrm{B}(\mathrm{S})$ & 19.2 & 17.2 & 44.5 & 25.9 & 26.6 \\
\hline dif & 12.3 & 7.5 & 24.8 & 7.5 & 12.9 \\
\hline \multicolumn{6}{|l|}{ Xgwm212 (5DL) } \\
\hline $\mathrm{A}(\mathrm{R})$ & 10.1 & 10.4 & 15.7 & 15.2 & 12.7 \\
\hline $\mathrm{B}(\mathrm{S})$ & 18.1 & 19.9 & 52.3 & 31.5 & 30.3 \\
\hline dif & 8 & 9.5 & 36.6 & 16.3 & 17.6 \\
\hline \multicolumn{6}{|c|}{ Xbarc $147 / X$ barc 180} \\
\hline $\mathrm{A} / \mathrm{A}(\mathrm{R} / \mathrm{R})$ & $2.6 \mathrm{a}$ & $6.1 \mathrm{a}$ & $16.0 \mathrm{a}$ & $13.2 \mathrm{a}$ & $9.5 \mathrm{a}$ \\
\hline $\mathrm{A} / \mathrm{B}(\mathrm{R} / \mathrm{S})$ & $7.0 \mathrm{a}$ & $8.4 \mathrm{ab}$ & $29.1 \mathrm{ab}$ & $12.2 \mathrm{a}$ & $14.1 \mathrm{a}$ \\
\hline $\mathrm{B} / \mathrm{A}(\mathrm{S} / \mathrm{R})$ & $14.8 \mathrm{ab}$ & $18.0 \mathrm{ab}$ & $30.7 \mathrm{ab}$ & $29.3 \mathrm{ab}$ & $23.2 \mathrm{ab}$ \\
\hline $\mathrm{B} / \mathrm{B}(\mathrm{S} / \mathrm{S})$ & $32.5 \mathrm{~b}$ & $26.7 \mathrm{~b}$ & $63.8 \mathrm{~b}$ & $40.3 \mathrm{~b}$ & $40.8 \mathrm{~b}$ \\
\hline dif & 29.9 & 20.6 & 47.8 & 28.1 & 26.7 \\
\hline \multicolumn{6}{|c|}{ Xbarc $147 / X g w m 212$} \\
\hline $\mathrm{A} / \mathrm{A}(\mathrm{R} / \mathrm{R})$ & $4.1 \mathrm{a}$ & $3.6 \mathrm{a}$ & $10.7 \mathrm{a}$ & $8.7 \mathrm{a}$ & $6.8 \mathrm{a}$ \\
\hline $\mathrm{A} / \mathrm{B}(\mathrm{R} / \mathrm{S})$ & $6.3 \mathrm{a}$ & $11.7 \mathrm{ab}$ & $36.9 \mathrm{ab}$ & $18.0 \mathrm{a}$ & $18.2 \mathrm{a}$ \\
\hline $\mathrm{B} / \mathrm{A}(\mathrm{S} / \mathrm{R})$ & $18.4 \mathrm{ab}$ & $20.8 \mathrm{bc}$ & $23.6 \mathrm{ab}$ & $24.6 \mathrm{a}$ & $21.9 \mathrm{a}$ \\
\hline $\mathrm{B} / \mathrm{B}(\mathrm{S} / \mathrm{S})$ & $32.8 \mathrm{~b}$ & $31.1 \mathrm{c}$ & $78.6 \mathrm{~b}$ & $48.8 \mathrm{~b}$ & $47.3 \mathrm{~b}$ \\
\hline dif & 28.7 & 27.5 & 67.9 & 40.1 & 40.5 \\
\hline \multicolumn{6}{|c|}{ Xbarc $147 /$ Xbarc $180 /$ Xgwm 212} \\
\hline $\mathrm{A} / \mathrm{A} / \mathrm{A}(\mathrm{R} / \mathrm{R} / \mathrm{R})$ & $1.8 \mathrm{a}$ & $4.1 \mathrm{a}$ & $12.1 \mathrm{a}$ & $8.3 \mathrm{a}$ & $6.7 \mathrm{a}$ \\
\hline $\mathrm{A} / \mathrm{A} / \mathrm{B}(\mathrm{R} / \mathrm{R} / \mathrm{S})$ & $3.5 \mathrm{a}$ & $8.7 \mathrm{a}$ & $20.9 \mathrm{a}$ & $19.4 \mathrm{ab}$ & $13.1 \mathrm{a}$ \\
\hline $\mathrm{A} / \mathrm{B} / \mathrm{A}(\mathrm{R} / \mathrm{S} / \mathrm{R})$ & $5.2 \mathrm{a}$ & $3.8 \mathrm{a}$ & $10.4 \mathrm{a}$ & $8.9 \mathrm{a}$ & $7.0 \mathrm{a}$ \\
\hline $\mathrm{A} / \mathrm{B} / \mathrm{B}(\mathrm{R} / \mathrm{S} / \mathrm{S})$ & $9.9 \mathrm{a}$ & $15.4 \mathrm{ab}$ & $59.8 \mathrm{ab}$ & $17.5 \mathrm{ab}$ & $25.6 \mathrm{a}$ \\
\hline B/A/A (S/R/R) & $16.9 \mathrm{ab}$ & $24.4 \mathrm{ab}$ & $19.7 \mathrm{a}$ & $15.6 \mathrm{ab}$ & $19.1 \mathrm{a}$ \\
\hline B/A/B (S/R/S) & $14.1 \mathrm{ab}$ & $15.7 \mathrm{ab}$ & $35.2 \mathrm{ab}$ & $34.2 \mathrm{~b}$ & $24.6 \mathrm{a}$ \\
\hline B/B/A (S/S/R) & $20.2 \mathrm{ab}$ & $13.3 \mathrm{a}$ & $26.9 \mathrm{a}$ & $24.4 \mathrm{ab}$ & $21.2 \mathrm{a}$ \\
\hline $\mathrm{B} / \mathrm{B} / \mathrm{B}(\mathrm{S} / \mathrm{S} / \mathrm{S})$ & $48.7 \mathrm{~b}$ & $44.1 \mathrm{~b}$ & $112.0 \mathrm{~b}$ & $61.2 \mathrm{c}$ & $66.5 \mathrm{~b}$ \\
\hline Dif & 46.9 & 40 & 101.6 & 52.9 & 59.8 \\
\hline
\end{tabular}

y Different letter indicates significant difference at $P<0.05$.

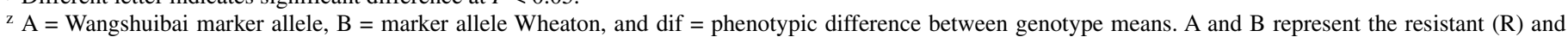
susceptible (S) alleles of the linked markers.

genetic variation. They may differ between the parents in some studies and not in others. For this reason, these minor QTL should be verified in multiple tests across different genetic backgrounds and in different environments before being used in marker-assisted breeding.

Results in this study suggested that type III resistance may be the consequence of type II and type I resistance. A previous study showed that type II and type III resistance might be controlled by independent genetic factors (30), whereas other studies suggested that type II resistance might be closely associated with type III resistance $(7,15)$. The discrepancy among studies may result from different inoculation conditions (field and greenhouse), genetic backgrounds, and the limited sizes of mapping populations that may lead to underestimation of QTL number, overestimation of QTL effects, and inability to quantify QTL interactions (5). Most FHB-resistance QTL detected in this study showed a pleiotropic effect on both DON content and FHB severity. The 3BS and 5AS QTL in Wangshuibai showed effects on both type II resistance and low DON content in this and a previous study (19). Four of the seven QTL for type III resistance on 3BS (two QTL), 5AS, and 7AL were coincident with the QTL for type II resistance. The QTL on 3BS, 5AS, and 5DL also showed type I resistance. The 1BL QTL showed only type III resistance in this study, but it was determined to have a minor effect on type II resistance (40). Only minor QTL on 1AS for low DON content showed no association with type I and type II resistance. Thus, QTL for FHB resistance, especially type II, seem to play an important role in lowering DON content in infected grain. Selection for type II resistance may lead to reduction in DON content in wheat cultivars.

\section{ACKNOWLEDGMENTS}

This project is partly funded by the United States Wheat and Barley Scab Initiative and National Research Initiative of the United States Department of Agriculture-The Cooperative State Research, Education, and Extension Service CAP grant no. 2006-55606-16629. Mention of trade names or commercial products in this article is solely for the purpose of providing specific information and does not imply recommendation or endorsement by the United States Department of Agriculture. This is contribution No. 07-70-5 from the Kansas Agricultural Experiment Station, Manhattan.

\section{LITERATURE CITED}

1. Bai, G. H., Desjardins, A. E., and Plattner, R. D. 2002. Deoxynivalenolnonproducing Fusarium graminearum causes initial infection, but does not cause disease spread in wheat spikes. Mycopathologia 153:91-98.

2. Bai, G. H., Guo, P. G., and Kolb, F. L. 2003. Genetic relationships among head blight resistant cultivars of wheat assessed on the basis of molecular markers. Crop Sci. 43:498-507.

3. Bai, G. H., and Shaner, G. E. 1994. Scab of wheat: Prospects for control. Plant Dis. 78:760-766.

4. Bai, G. H., and Shaner, G. E. 2004. Management and resistance in wheat and barley to Fusarium head blight. Annu. Rev. Phytopathol. 42:135-161.

5. Beavis W. B. 1998. QTL analyses: Power, precision, and accuracy. In: Molecular Dissection of Complex Traits. A. H. Patterson, ed. CRC Press, Boca Raton, FL.

6. Berek, L., Petri, I. B., Mesterházy, A., Teren, J., and Molnar, J. 2001. Effects of mycotoxins on human immune functions in vitro. Toxicol. Vitro 15:25-30.

7. Chen, J., Griffey, C. A., Saghai Maroof, M. A., Stromberg, E L., Biyashev, R. M., Zhao, W., Chappell, M. R., Pridgen, T. H., Dong, Y., and Zeng, Z. 2006. Validation of two major quantitative trait loci for Fusarium 
head blight resistance in Chinese wheat line W14. Plant Breed. 125:99101.

8. Cuthbert, P. A., Somers, D. J., Thomas, J., Cloutier, S., and Brule-Babel, A. 2006. Fine mapping Fhb1, a major gene controlling Fusarium head blight resistance in bread wheat (Triticum aestivum L.). Theor. Appl. Genet. 112:1465-1472.

9. Doerge, R. W., and Churchill, G. A. 1996. Permutation tests for multiple loci affecting a quantitative character. Genetics 142:285-294.

10. Gilsinger, J., Kong, L., Shen, X., and Ohm, H. 2005. DNA markers associated with low Fusarium head blight incidence and narrow flower opening in wheat. Theor. Appl. Genet. 110:1218-1225.

11. Guyomarc'h, H., Sourdille, P., Charmet, G., Edwards, K., and Bernard, M. 2002. Characterization of polymorphic microsatellite markers from Aegilops tauschii and transferability to the D-genome of bread wheat. Theor. Appl. Genet. 104:1164-1172.

12. Jansen, C., von Wettstein, D., Schäfer, W., Kogel, K. H., Felk, A., and Maier, F. J. 2005. Infection patterns in barley and wheat spikes inoculated with wild-type and trichodiene synthase gene disrupted Fusarium graminearum. Proc. Natl. Acad. Sci. USA 102:16892-16897.

13. Kang, Z., and Buchenauer, H. 1999. Immunocytochemical localization of Fusarium toxins in infected wheat spikes by Fusarium culmorum Physiol. Mol. Plant Pathol. 55:275-288.

14. Kosambi, D. D. 1944. The estimation of map distances from recombination values. Ann. Eugen. 12:172-175.

15. Lemmens, M., Scholz, U., Berthiller, F., DallAsta, C., Koutnik, A., Schuhmacher, R., Adam, G., Buerstmayr, H., Mesterházy, A., Krska, R., and Ruckenbauer, P. 2005. The ability to detoxify the mycotoxin deoxynivalenol colocalizes with a major quantitative trait locus for Fusarium head blight resistance in wheat. Mol. Plant-Microbe Interact. 18:1318-1324.

16. Lin, F., Kong, Z. X., Zhu, H. L., Xue, S. L., Wu, J. Z., Tian, D. G., Wei, J. B., Zhang, C. Q., and Ma, Z. Q. 2004. Mapping QTL associated with resistance to Fusarium head blight in the Nanda2419 $\times$ Wangshuibai population II: type II resistance. Theor. Appl. Genet. 109:1504-1511.

17. Lin, F., Xue, S. L., Zhang, Z. Z., Zhang, C. Q., Kong, Z. X., Yao, G. Q., Tian, D. G., Zhu, H. L., Li, C. J., Cao, Y., Wei, J. B., Luo, Q. Y., and Ma, Z. Q. 2006. Mapping QTL associated with resistance to Fusarium head blight in the Nanda2419 $\times$ Wangshuibai population II: Type I resistance. Theor. Appl. Genet. 112:528-553.

18. Liu, S., and Anderson, J. A. 2003. Marker assisted evaluation of Fusarium head blight resistant wheat germplasm. Crop Sci. 43:760-766.

19. Ma, H. X., Zhang, K. M., Gao, L., Bai, G. H., Chen, H. G., Cai, Z. X., and Lu, W. Z. 2006. Quantitative trait loci for resistance to Fusarium head blight and deoxynivalenol accumulation in Wangshuibai wheat under field conditions. Plant Pathol. 55:739-745.

20. Mardi, M., Buerstmayr, H., Ghareyazie, B., Lemmens, M., Mohammadi, S. A., Nolz, R., and Ruckenbauer, P. 2005. QTL analysis of resistance to Fusarium head blight in wheat using a Wangshuibai-derived population. Plant Breed. 124:329-333.

21. Mesterházy, A. 1995. Types and components of resistance to Fusarium head blight. Plant Breed. 114:377-386.

22. Mirocha, C. J., Kolaczkowski, E., Xie, W., Yu, H., and Jelen, H. 1998. Analysis of deoxynivalenol and its derivatives (batch and single kernel) using gas chromatography/mass spectrometry. J. Agric. Food Chem. 46:1414-1418

23. Parry, D.W., Jenkinson, P., and McLeod, L. 1995. Fusarium ear blight (scab) in small-grain cereals a review. Plant Pathol. 44:207-238.
24. Pestsova, E., Ganal, M. W., and Röeder, M. S. 2000. Isolation and mapping of microsatellite markers specific for the D genome of breed wheat. Genome 43:689-697.

25. Röeder, M. S., Plaschke, J., Wendehake, K., Plaschke, J., Tixer, M. H., Leroy, P., and Ganal, M. W. 1998. A microsatellite map of wheat. Genetics 149:2007-2023.

26. Saghai Maroof, M. A., Soliman, K. M., Jorgensen, R. A., and Allard, R. W. 1984. Ribosomal DNA spacer length polymorphism in barley: Mendelian inheritance, chromosomal location, and population dynamics. Proc. Natl. Acad. Sci. USA 81:8014-8018.

27. Shen, X., Ittub, M., and Ohm, H. W. 2003. Quantitative trait loci conditioning resistance to Fusarium head blight in wheat line F201R. Crop Sci. 43:850-857.

28. Simpson, D. R., Weston, G. E., Turner, J. A., Jennings, P., and Nicholson, P. 2001. Differential control of head blight pathogens of wheat by fungicides and consequences for mycotoxin contamination of grain. Eur. J. Plant Pathol. 107:421-431.

29. Singh, R. P., Ma, H., and Rajaram, S. 1995. Genetic analysis of resistance to scab in spring wheat cultivar Frontana. Plant Dis. 79:238-240.

30. Somers, D. J., Fedak, G., and Savard, M. 2003. Molecular mapping of novel genes controlling Fusarium head blight resistance and deoxynivalenol accumulation in spring wheat. Genome 46:555-564.

31. Somers, D. J., Isaac, P., and Edwards, K. 2004. A high-density microsatellite consensus map for bread wheat (Triticum aestivum L.). Theor. Appl. Genet. 109:1105-1114.

32. Song, Q. J., Shi, J. R., Singh, S., Fickus, E. W., Costa, J. M., Lewis, J., Gill, B. S., Ward, R., and Cregan, P. B. 2005. Development and mapping of microsatellite (SSR) markers in wheat. Theor. Appl. Genet. 110:550-560.

33. Sourdille, P., Cadalen, T., Guyomarc'h, H., Snape, J. W., Perretant, M. R., Charmet, G., Boeuf, C., Bernard, S., and Bernard, M. 2003. An update of the Courtot $\times$ Chinese Spring intervarietal molecular marker linkage map for the QTL detection of agronomic traits in wheat. Theor. Appl. Genet. 106:530-538.

34. Steiner, B., Lemmens, M., Griesser, M., Scholz, U., Schondelmaier, J., and Buerstmayr, H. 2004. Molecular mapping of resistance to Fusarium head blight in the spring wheat cultivar Frontana. Theor. Appl. Genet. 109:215-224.

35. van Ooijen, J. W., and Voorips, R. E. 2001. JoinMap 3.0, Software for the calculation of genetic linkage maps. Published online by Plant Research International, Wageningen, the Netherlands.

36. Wang, S., Basten, C. J., and Zeng, Z. B. 2006. Windows QTL Cartographer 2.5. Published online by the Department of Statistics, North Carolina State University, Raleigh.

37. Windels, C. E. 2000. Economic and social impacts of Fusarium head blight: Changing farms and rural communities in the northern Great Plains. Phytopathology 90:17-21.

38. Xu, D. H., Juan, H. F., Nohda, M., and Ban, T. 2001. QTL mapping of type I and type II resistance to FHB in wheat. Pages 40-42 in: Proc. National Fusarium Head Blight Forum. R. W. Ward, ed. Michigan State University, East Lansing. (http://www.scabusa.org/publications.html)

39. Yu, J. B., Bai, G. H., Cai, S. B., and Ban, T. 2006. Marker-assisted characterization of Asian wheat lines for resistance to Fusarium head blight. Theor. Appl. Genet. 113:308-320.

40. Zhou, W. C., Kolb, F. L., Yu, J. B., Bai, G. H., Boze, L. K., and Domier, L. L. 2004. Molecular characterization of Fusarium head blight resistance in Wangshuibai with simple sequence repeat and amplified fragment length polymorphism markers. Genome 47:1137-1143. 